\title{
Los nuevos imperialismos y las luchas por la paz ${ }^{1}$
}

\author{
Napoleón Saltos Galarza \\ Universidad Central del Ecuador \\ wnsaltosg@yahoo.es
}

Recibido: 3 - enero - 2018 / Aceptado: 1 - febrero - 2018

\section{Resumen}

El texto aborda las trasmutaciones del capitalismo tardío, desde dos perspectivas, los cambios estructurales y las modificaciones de las contradicciones interimperialistas, y del dominio de los pueblos. En el primer aspecto, no estamos en la fase de transición, sino en un tiempo previo, marcado por la decadencia del capitalismo mundial, pero con la ausencia de un horizonte utópico alternativo, aunque podemos ubicar semillas antisistémicas desde la resistencia de los pueblos y experiencias parciales. Estamos ante las formas extremas de la modernidad liberal, que concluye el proceso de extrañamiento del sujeto individual, ahora consigo mismo, en un poshumanismo, que tiene como horizonte distópico la inteligencia artificial y la racionalidad cínica. En el segundo aspecto, la paradoja es la presencia de una especie de "ultraimperialismo", con la concentración extrema de la riqueza y de nuevas formas de pobreza, exclusión y desechabilidad de pueblos y continentes; pero con la agudización de las contradicciones interimperialistas. Enfrentamos a los imperialismos, en plural. No se cumplió la expectativa del "fin de la historia" y del triunfo de Occidente, después de la Caída del Muro, sino que entramos en una fase de guerras y conflictos en diversa escala. No se trata de una reedición de la "Guerra Fría" entre dos polos, sino de un proceso complejo: la contradicción entre el eje Norte-Sur, liderado por el imperialismo norteamericano en relación con las potencias tradicionales EE.UU.-UE-Japón, y el eje Este-Oeste, liderado por la alianza China-Rusia en relación con los BRICs; y la presencia de contradicciones al interior de cada polo entre dinámicas globalistas-financieras y nacionalistas-posindustriales. El fin del orden westfaliano y el debilitamiento de los estados-nacionales, se combina con el vacío de un Estado mundial, que trata de ser copado por el imperialismo norteamericano, como guardián mundial, en base a una estrategia

1 Una versión inicial fue presentada en CWM's Resisting Empire \& Militarization: Reasserting the Sacredness of Seas, Lands and Lives Conference on 10 - 12 December 2018 in Mexico City, Mexico. 
guerrerista y el refuerzo de tendencias de nuevas carreras armamentistas. En la relación con los pueblos del Sur, la modificación principal de los nuevos imperialismos está en los dispositivos de "acumulación por desposesión" y en la delegación de guerras civiles enmarcadas en disputas geopolíticas, con dinámicas de vaciamiento de los estados nacionales. Con ello, las fronteras de las guerras y los puntos calientes de los conflictos se ubican en el entrecruzamiento de tres dinámicas: el control de los cinco monopolios estratégicos, sobre todo vinculados a la renta tradicional y la renta tecnológica; las confrontaciones civilizatorias-religiosas-étnicas; y las disputas geopolíticas. La pregunta final es sobre los caminos de la paz desde los pueblos y desde el Sur: negociaciones o rendiciones, resistencias y desconexiones, luchas ético-políticas.

Palabras clave: imperialismos, Estado-nacional, guerra, paz, pueblos.

\section{Abstract}

The text deals with the transmutations of late capitalism, from two perspectives, structural changes and modifications of inter-imperialist contradictions, and the domination of peoples. In the first aspect, we are not in the transition phase, but in a previous time, marked by the decadence of world capitalism, but with the absence of an alternative utopian horizon, although we can locate antisystemic seeds from the resistance of peoples and experiences partial We are facing the extreme forms of liberal modernity, which concludes the process of estrangement of the individual subject, now with himself, in a posthumanism, which has as a dystopian horizon artificial intelligence and cynical rationality. In the second aspect, the paradox is the presence of a kind of "ultra-imperialism", with the extreme concentration of wealth and new forms of poverty, exclusion and disposability of peoples and continents; but with the intensification of inter-imperialist contradictions. We face imperialisms, in the plural. The expectation of the "end of history" and the triumph of the West, after the Fall of the Wall, was not fulfilled, but we entered into a phase of wars and conflicts on different scales. It is not a reissue of the "Cold War" between two poles, but a complex process: the contradiction between the North-South axis, led by US imperialism in relation to the traditional US-EU-Japan powers, and the East-West axis, led by the China-Russia alliance in relation to the BRICs; and the presence of contradictions within each pole between globalist-financial dynamics and nationalist-postindustrial dynamics. The end of the Westphalian order and the weakening of the nation-states, is combined with the emptiness of a world state, which tries to be taken over by the North American imperialism, as world guardian, based on a war strategy and the reinforcement of tendencies of new arms races. In the relationship with the peoples of the South, the main modification of the new imperialisms is in the devices of "accumulation by dispossession" and in the delegation of civil wars framed in geopolitical disputes, with dynamics of emptying of the national states. With this, the borders of wars and the hot spots of conflicts are located in the interweaving of three dynamics: the control of the five strategic monopolies, mainly linked to traditional income and technological income; civilizational-religious-ethnic confrontations; and geopolitical disputes. The final question is about the paths of peace from the people and from the South: negotiations or surrenders, resistance and disconnections, ethical-political struggles.

Keywords: Imperialism / National-State / War / Peace / Peoples 
Conocer al imperio es parte de combatirlo (Callinicos 2011, 161) La guerra sólo se preocupa de la fachada, de la apariencia (Melville 1891)

\section{Trasmutaciones}

$\mathrm{D}$ espués de la ilusión del "fin de la historia" (Fujuyama 1988), proclamada a raíz de la implosión del Unión Soviética, no entramos en el siglo de la "pax de Occidente" basada en el triunfo del capital, ${ }^{2}$ no se instauró una hegemonía unilateral, encabezada por la tríada USA-UE-Japón; pasamos a un descentramiento multilateral bajo dos dinámicas centrales: el predominio de una hegemonía estructural del capital liberal, en su forma pos-humanista (Ramas y Tamames 2018) y en su fase de decadencia; y un orden multilateral con diversos nodos, marcados no solo por la dimensión geopolítica, sino por el retorno de identidades étnicas, nacionales y religiosas.

No se trata únicamente de un nuevo ciclo de lucha por la hegemonía, en los términos anunciados por Giovanni Arrighi (2014), entre las potencias tradicionales, encabezadas por Estados Unidos; y las potencias emergentes, en torno a los BRICs, encabezadas geoeconómicamente por China; una especie de reedición de la "Guerra Fría”, con dos polos de ordenamiento. Más bien asistimos a una trasmutación al interior de cada uno de los polos, lo que modifica las fronteras de las disputas y alianzas, con la presencia de líneas exteriores e interiores.

Dentro de Occidente hay una fractura entre los "nacionalistas-pragmáticos", representados por Trump y los brexistas, en un movimiento de fortalecimiento hacia adentro y recentramiento de los procesos del capital; y las tendencias "globalistas-geopolíticas", representadas por el establishment y la tecnocracia multilateral, que buscan consolidar la tendencia estructural del dominio del capital, en una versión de "neoliberalismo progresista" a nivel local y un funcionamiento como imperio-imperialismo a nivel global.

Pero también entre los BRICs hay dinámicas de acercamiento y diferenciación. La alianza chino-rusa opera como ordenador en la confrontación con las potencias tradicionales, pero con amenazas de conflictos dentro del área euroasiática que buscan consolidar. En China, dos dinámicas disputan las orientaciones y las políticas tanto internas como externas: la presencia de una China continental, con fuerte presencia campesino-agraria y formas tradicionales de vida, con posiciones más conservadoras y nacionalistas; y la fuerza de una China costera, globalista y orientada a visiones del capitalismo liberal. Pero, además, existen los avatares de los procesos propios de otras economías emergentes, como India o Brasil, que disputan espacios de control, en movimientos de acercamiento y alejamiento respecto al eje occidental y al eje euro-asiático.

2 "Lo que podríamos estar presenciando no sólo es el fin de la guerra fría, o la culminación de un período específico de la historia de la posguerra, sino el fin de la historia como tal: esto es, el punto final de la evolución ideológica de la humanidad y la universalización de la democracia liberal occidental como la forma final de gobierno humano" (Fujuyama 1988). 
Por ello, en el ordenamiento mundial habría que ubicar el entrecruzamiento de estas dinámicas múltiples, al menos un juego en cruz con cuatro atractores-dinámicas principales, una estructura en mutación, en un ambiente de incertidumbre. Todavía no podemos hablar de la fase de una transición pos-capitalista/pos-patriarcalista, no estamos todavía en el "Renacimiento"; quizás estamos en el estadio previo, la decadencia y complejización del orden mundial capitalista, que se mueve en sus formas más extremas económico-culturales-políticas; y la emergencia de semillas de resistencias y alternativas, sin posibilidad de proclamar un horizonte utópico seguro. Movimientos de resistencia y ensayos parciales, locales, temporales de rebasamiento del mundo capitalista-patriarcal, a menudo reabsorbidos por la dinámica general-estructural del capital y el patriarcalismo.

De modo, que la comprensión del momento actual del capitalismo-imperialismo, implica un doble proceso: analizar las tendencias estructurales del capitalismo tardío, y ubicar las contradicciones y luchas por la hegemonía, por la orientación, más que conducción, del mundo, analizar la presencia de nuevos imperialismos, para poder definir la ubicación y alineamiento de los pueblos y países del Sur.

\section{Trasmutaciones económicas}

Bajo la lógica de la mundialización del capital, el imperialismo contemporáneo se ha trasmutado. En la dimensión económica asistimos a un doble proceso: la creciente centralización monopólica de la acumulación de capitales en manos de un reducido número de transnacionales financieras-rentistas, lo que fundamenta la constitución de un imperialismo centralizado. Y la modificación de las contradicciones interimperialistas y del orden mundial, y sus relaciones con las periferias.

Se realiza aparentemente la previsión de Berstein del "ultraimperialismo", pero no en el sentido anunciado, como antesala pacífica de la entrada al socialismo; sino más bien como centralización decadente del capital, sin perspectivas de transición. El recorrido de flujos dentro de las transnacionales y sus filiales, así como entre transnacionales dominantes, impide al capital "destruir" los capitales ineficientes en períodos de crisis, y más bien acentúa las tendencias especulativas y criminales de la reproducción ampliada del capital mundial. De modo que la crisis de sobrecrecimiento, que arrancó en los años 80 , no ha logrado ser superada, sino que los estallidos sucesivos de las burbujas financieras forman parte de los flujos de la acumulación de capitales, en un movimiento que va de las periferias hacia el centro.

Sobre todo a partir de la crisis punto.com del 2001, el camino elegido por el capital estadounidense fue "el desarrollo de un auge clásico del crédito especulativo, con todo tipo de estafas e "innovaciones" financieras poco fiables (obligaciones de deuda colateralizadas, medios de inversión estructurado y similares) y una corriente de adquisiciones de empresas por firmas de capital privado mediante créditos baratos cuyo principal efecto fue, cuando el boom inevitablemente se desplomó, difun- 
dir las malas deudas a lo largo del sistema financiero, provocando una parálisis que ocasionó una importante recesión mundial" (Callinicos 2011, 141).

"El 80\% del comercio mundial se explica en tanto comercio entre transnacionales (ETN's) y el 50\% como intra-trasnacional (ETN). El 48\% de la riqueza social producida/ensamblada en la economía de las transnacionales tiene asiento en paraísos fiscales (Londres-Delaware-Hong Kong, etc.) (...). El 48\% circula por los mal llamados "paraísos fiscales" y el $52 \%$ en los estados nacionales, o sea, el $52 \%$ es visible a las instituciones de la administración de los países. El 97\% de las ganancias y rentas anuales socialmente producidas terminan en los llamados paraísos fiscales. Estos paraísos son parte de una nueva arquitectura financiera global que se configura como un sistema extraterritorial (extra-Estado nación)" (Dierckxsens y Fomento 2018).

Según Oxfam, en 2017, "el número de personas cuyas fortunas superan los mil millones alcanzó su máximo histórico, con un nuevo milmillonario cada dos días. En este momento hay 2.043 milmillonarios (en dólares) en todo el mundo, de los que nueve de cada diez son hombres. La riqueza de estos milmillonarios también experimentó un enorme crecimiento, lo suficiente como para poder terminar con la extrema pobreza en el mundo hasta siete veces. El 82\% del crecimiento de la riqueza mundial durante el último ańo fue a parar a manos del $1 \%$ más rico, mientras que la del 50\% más pobre de la población mundial no aumentó lo más mínimo (OXFAM internacional 2018, 9).

Un estudio de la Universidad de Zúrich, sobre la base del análisis de 37 millones de compañías en el mundo, estableció un "súper núcleo" de 147 empresas transnacionales, estrechamente unidas, que controlan el $40 \%$ de la economía mundial. La gran mayoría de estas empresas son entidades financieras de Estados Unidos y el Reino Unido (Coghlan y MacKenzie 2011).

La directora gerente del FMI, Christine Lagarde, declaró al inicio de octubre de 2018 que "desde 1980, el 1\% superior se ha hecho con el doble de ganancias del crecimiento que el 50\% inferior" (Elliot 2018).

No se trata de un tema solo de desigual distribución de la riqueza, sino del copamiento monopólico de los campos claves de la economía. "Las tendencias de la evolución del capitalismo contemporáneo se articulan en torno al refuerzo de (...) "cinco monopolios" que caracterizan a la mundialización polarizante del imperialismo contemporáneo: (i) el monopolio de las nuevas tecnologías; (ii) el del control de los flujos financieros a escala mundial; (iii) el control del acceso a los recursos naturales del planeta; (iv) el control de los medios de comunicación; (v) el monopolio de las armas de destrucción masiva”.

El funcionamiento endógeno transnacional del capital global termina por llevar las crisis a un movimiento en espiral, en un salto permanente hacia adelante, pero sin salidas al círculo ascendente; aunque tampoco con las expectativas de una crisis final inmediata. 
El tema no es solo de relaciones sociales económicas y de concentración monopólica de la propiedad y la riqueza; sino que hay un soporte material en la apropiación de las nuevas fuerzas productivas resultado de la tercera y la cuarta revolución científico-técnica, en particular de la revolución informática, genética y de administración. Aquí se asienta la contradicción principal: la humanidad, por primera vez está ante la posibilidad de superar la escasez y de crear condiciones para una civilización planetaria; pero esas potencialidades han sido absorbidas por la modernidad capitalista y transmutadas en nuevas formas de dominio y control. El poder se trasmuta en thanatos-bio-poder y el objeto es el señorío sobre la vida y la muerte ya no solo de individuos y pueblos, sino de continentes, la frontera última es la supervivencia de la humanidad. El cambio climático, más que un riesgo para la madre-naturaleza, es una alarma para la persistencia de la vida humana.

Con ello el mundo entra en la fase tardía del capitalismo que teóricamente no encuentra su propia caracterización, pues ha sido más bien pensada como pos-capitalismo, pos-modernismo, una transición que se mide con el pasado. El capitalismo tardío se presenta ya no solo como anti-humanismo, sino como pos-humanismo, en la construcción del homo desnudo incluso de su propia referencia, para buscar la distopía en un pos-positivismo esperanzado en la salvación desde la inteligencia artificial y la robótica, la sociedad sin trabajadores. La utopía comunista de la sociedad sin clases transformada en la distopía de una Mátrix ordenadora. Dentro de esta distopía está también la seducción de los juegos armamentísticos y el anclamiento del derecho a la seguridad, con el símbolo del derecho a portar armas para la defensa propia, como soportes de la segurización de la política y del paso al "Estado de seguridad".

"El afijo "pos-" denota un estado de lo que dejó de ser (muchas veces) renunciando a la caracterización de lo que se ha llegado a ser" (Jaramillo 2013). Aunque allí también se presenta el estado de la transición, un momento previo al renacimiento, en que podemos afirmar más el mundo que entra en decadencia, que el horizonte que surge. Los fracasos de los tres intentos del siglo XX de salidas ante el dominio del capitalismo, el socialismo real, las luchas de liberación y los proyectos socialdemócratas, disuelven los horizontes utópicos globales.

No se trata de presentar una imagen apocalíptica barbarie o barbarie, sino más bien de ubicar la tendencia de control global, una especie de Mátrix que funciona autopoiéticamente. La base material es el paso a la subsunción real del consumo al capital. "La estructura material de los valores de uso ha quedado determinada de tal manera que responde a las necesidades de la explotación y acumulación de plusvalor. En consecuencia, el sometimiento de los seres humanos ya no es solo económico y político, ni solamente ideológico y cultural, sino también fisiológico; ahora el modo de producción capitalista moldea nuestro modo de vida y el sometimiento político es también psicosocial y, por tanto, sexual" (Veraza 2008). El capital y el Estado moderno han colonizado todos los espacios de vida en aras de la lógica de la acumulación y la ganancia. 
En este salto, el capitalismo tardío mezcla las formas del ciclo de financierización de la acumulación con las formas de acumulación originaria y sus variaciones como acumulación por desposesión; es decir, opera el dominio global del capital financiero-rentista sobre la sociedad y la naturaleza. En el componente rentista, se principaliza el control de la nueva renta tecnológica, con la subsistencia de la explotación y control de la renta tradicional de la tierra y los recursos naturales estratégicos.

Dentro de esta lógica, la desmesura de la sobreacumulación financierizada ya no opera solo sobre los excesos del valor de cambio, sino que requiere diversas estrategias de recorte de la vida de los valores de uso, desde los manejos tecnológicos para la obsolescencia de las mercancías, las estrategias del consumismo y de la moda, hasta la mantención de un estado de guerra permanente y de diversas formas de guerras localizadas prolongadas y de carreras armamentistas, a fin de acelerar la circulación de los valores de uso y de las condiciones de la acumulación. El capital mundial funciona sobre dos dinámicas contradictorias: en la valorización el crecimiento especualtivo, la sobreabundancia de capitales financieros sin posibilidad de enraizarse en procesos reales-productivos; $y$ en los procesos de producción y circulación, la creación de una escasez ficticia, artificial, que produce ciclos permanentes de ganancia extraordinaria, tanto por el lado de la sobreexplotación de la fuerza de trabajo, como por la sobreexplotación de la naturaleza. En la cúspide de la competencia entre monopolios transnacionales y potencias geopolíticas está la alianza entre el capital financiero y los negocios bélicos; ya no se trata únicamente del complejo industrial-militar, la añoranza de Trump, sino del complejo financiero-rentista-militar.

Desde el Sur, se trata, sobre todo, de descubrir las fisuras de este control totalitario, la presencia de semillas antisistémicas, otras formas de vida, que anuncian la posibilidad de alternativas. La puerta es una lectura desde nuestra identidad y nuestra diferencia: "para el esclarecimiento del conjunto, no resulta inútil que nosotros figuremos en uno de los polos de la comparación. Este es quizá el punto más importante: volvemos a encontrar ahí aquello que hemos llamado la comparación radical, en la que nosotros mismos estamos implicados" (Dumont 1987).

III. La modificación del carácter de las contradicciones en el marco del funcionamiento imperial-imperialista, no como fase, sino como carácter del capitalismo mundial.

3.1. La contradicción entre el eje norte-sur, liderado por Estados Unidos, en la tríada con la Unión Europea y Japón: y el eje este-oeste, liderado por China-Rusia en el bloque de los BRICs.

"Cualquier comprensión del imperialismo contemporáneo que no tenga en cuenta las tensiones y las fracturas potenciales entre las potencias principales es peligrosamente unilateral" (Callinicos 2011, 151).

La presencia de China, "como el territorio principal de excedente de capital mundial para asentarse y obtener sus beneficios y como el principal mercado de exportación para los productores de materias primas, así como fabricantes de bienes de capital" (Hung 2008, 170, citado en Callinicos 2011, 142) da una salida temporal a 
la crisis global, representa la última posibilidad de una desplazamiento geo-económico del capital, con un crecimiento vertiginoso de China en las últimas cuatro décadas, dentro de una estrategia de aseguramientos mutuos con la economía norteamericana.

Este recurso empieza a encontrar su límite tanto por las dinámicas internas de la economía china, al acentuarse las desigualdades en la constitución de monopolios privados, altamente concentradores de la riqueza, así como en las desigualdades territoriales campo-ciudad, interior-litoral; como por la mutación de la relaciones interimperialistas, sobre todo ante el giro de Trump hacia la recomposición del complejo industrial-militar como sustento de la propuesta "nacionalista" de nuevos crecimientos de la economía norteamericana, con el correlato de la guerra económica, y el desplazamiento de las fronteras principales de conflictos belicistas desde la estrategia de combate al terrorismo y el eje del mal, a la confrontación con la expansión de las potencias emergentes, el desplazamiento geográfico de las fronteras de conflictos hacia el Pacífico.

En el período Obama esta contradicción se movía dentro de una estrategia geopolítica, liderada por el capital financiero y los organismos multilaterales, las fronteras estaban en las luchas contra el terrorismo y el aseguramiento del dominio militar. La entrada de Trump y las tendencias brexistas buscan recuperar la lógica de la corporación industrial-militar, por lo cual la dinámica mundial se presenta sobre todo como guerra económica, con el desplazamiento de fronteras a la principalización del enfrentamiento con China y el crecimiento de la carrera armamentista.

No se trata solo de una guerra económica, con imposición de aranceles, disputas sobre la moneda global, control de mercados, sino también de una escalada militarista. "La estrategia estadounidense en Asia implica, particularmente, intentar mantener la subordinación estratégica de Japón y, más generalmente, desarrollar una coalición de los Estados capaces de contener a China" (Callinicos 2011, 152).

Una de las fronteras principales entre la expansión china y la contención norteamericana está en el Mar de China Meridional, ubicado en el extremo sudoriental de Asia. "Es una extensión occidental del océano Pacífico que lo enlaza con el océano Índico por medio del estrecho de Malaca. Cubre un área de grandes dimensiones que se extiende de norte a sur desde las costas meridionales de China hasta el archipiélago indonesio y, en dirección de este a oeste, desde Filipinas hasta las penínsulas de Indochina y Malaca. Por ser vía de enlace entre los océanos Pacífico e Índico, el mar de China Meridional es una zona de tránsito naval de enorme relevancia, pues permite la comunicación entre Asia Oriental con el sur de Asia y el Medio Oriente. Por esta zona, diariamente transitan cientos de barcos cargueros repletos de contenedores con productos manufacturados en alguno de los países de Asia Oriental y sudoriental con destino a los mercados del sudeste asiático, el Medio Oriente o incluso Europa. En dirección contraria, dicho mar es surcado por buque-tanques que transportan petróleo desde el golfo Pérsico hacia alguno de los países industrializados de Asia Oriental y sudoriental, como China, Corea del Sur, Filipinas, Japón, Singapur y Taiwán. Por si esto no fuera suficiente, dicho mar posee valiosos recursos naturales, pues se estima que guarda yacimientos de petróleo y gas natural, así como incontables bancos de peces de 
gran valor para la industria pesquera. Se trata de un espacio marino de gran relevancia para la economía mundial en su conjunto y para los países del este y el sudeste de Asia, fuertemente vinculados con los mercados occidentales gracias a su condición como economías exportadoras de una parte considerable de los bienes manufacturados que muchos consumidores utilizamos cotidianamente" (Hernández 2018).

Los ejercicios de guerra y las maniobras de acuerdos con los actores dentro del teatro de conflicto se multiplican, para mantener "atrapada a China dentro de su región” y evitar la competencia global. La emergencia de India y otras potencias regionales puede abonar a este objetivo.

Este teatro se articula a la estrategia de la tríada para retener a Rusia dentro de un cerco económico-bélico, que tiene sus puntos calientes en el conflicto de Ucrania y en la expansión de una cadena de bases militares en las fronteras geográficas. Y se expande al largo conflicto en Medio Oriente, que ha pasado de una fase expansiva e intervencionista del imperialismo norteamericano en sucesivas guerras inconclusas en Afganistán, Irak, Libia; a una fase de contención y repliegue.

La respuesta estratégica de la alianza ruso-china-iraní ha desplazado el límite hacia las guerras de Medio Oriente, en donde la guerra de Siria se presenta como la frontera de reordenamiento geoestratégico. La política de Trump contra Irán, busca llevar las fronteras a las líneas interiores logradas con los acuerdos en el período de Obama. En esta frontera el conflicto toma la forma de confrontaciones bélicas, cruzadas por enfrentamientos étnico-religiosos y por la disputa del control monopólico de los recursos estratégicos.

El conflicto palestino-israelí es la condensación de todas estas confrontaciones: prolonga un conflicto resultado de la distribución bipolar del mundo después de la Segunda Guerra Mundial, allí está también la frontera actual económico-política del control de Medio Oriente, y, sobre todo, está la forma extrema de cerco y exterminio del pueblo palestino, sin la presencia de un poder global que pueda resolverlo.

El enfrentamiento con China toma sobre todo la forma de una guerra económica, con la exacerbación de la carrera armamentista preparatoria a las posibilidades de una confrontación bélica. El expansionismo chino busca evitar la confrontación directa y desarrolla estrategias de penetración y control económico global, en torno a la nueva Ruta de la Seda que une Asia y Europa, el liderazgo en los acuerdos de libre mercado global ante el vacío dejado por la política Trump, la disputa del monopolio monetario del dólar, y las políticas de inversión y créditos hacia el Sur; mientras avanza en el poderío bélico todavía defensivo.

Allí reside una cuestión teórico-política para una visión crítica: definir el carácter del proceso chino, responder a la pregunta si se trata de una variación del imperialismo, o si se puede hablar de socialismo. Este tema rebasa el objetivo de este texto y requiere un tratamiento específico. Sin embargo, se puede avanzar algunos elementos. Algunos sectores reservan el carácter imperialista al Estado norteamericano; y a partir de una lectura parcial reproducen el esquema de una nueva Guerra Fría, en la que se enfrentaría el mundo capitalista, encabezado por la tríada USA-UE-Japón, frente al Gran Sur, dentro del cual se ubica a la República Popular China. No se toma en cuenta que la lógica capitalista 
de acumulación, basada en la relación capital-trabajo, funciona al interior en procesos de monopolización privada creciente, con una fuerte presencia del Estado y del Partido, como también en las relaciones internacionales, incluidas con el Sur, bajo formas de acumulación por desposesión. El expansionismo chino adopta una vía más geoeconómica, que geomilitar. Al mismo tiempo la presencia del eje Este-Oeste articulado en torno a los BRICs y el papel de la política internacional de China, son un contrapeso al dominio unilateral del imperialismo norteamericano y han permitido espacios de autonomía en diversos conflictos. En este sentido, hay contradicciones significativas entre los dos polos, que toman la forma de contradicciones interimperialistas, más que una contradicción entre sistemas diferenciados. Por tanto, se requiere una política diferenciada desde los movimientos sociales y los pueblos del Sur, basada en la independencia y no-alineamiento, más allá de las estrategias del mal menor.

\subsection{Disputas armamentistas}

Se suceden las noticias sobre nuevas carreras armamentistas, incrementos de presupuestos militares, nuevos tipos de armamentos, denuncia de tratados de control armamentista. Trump anuncia que pondrá fin a al Tratado firmado en 1987 entre Gorbachov y Reagan para la eliminación de los misiles nucleares de mediano y corto alcance. Anuncia que también hay las intenciones de bloquear el Tratado New Star, firmado con Rusia en 2010 y que expirará en 2021. El cálculo de las carreras armamentista ya no es solo geopolítico, sino más bien geoeconómico.

De acuerdo al Informe SIPRI, 2018: (SIPRI 2018)

\section{Gasto militar mundial 1988-2017}

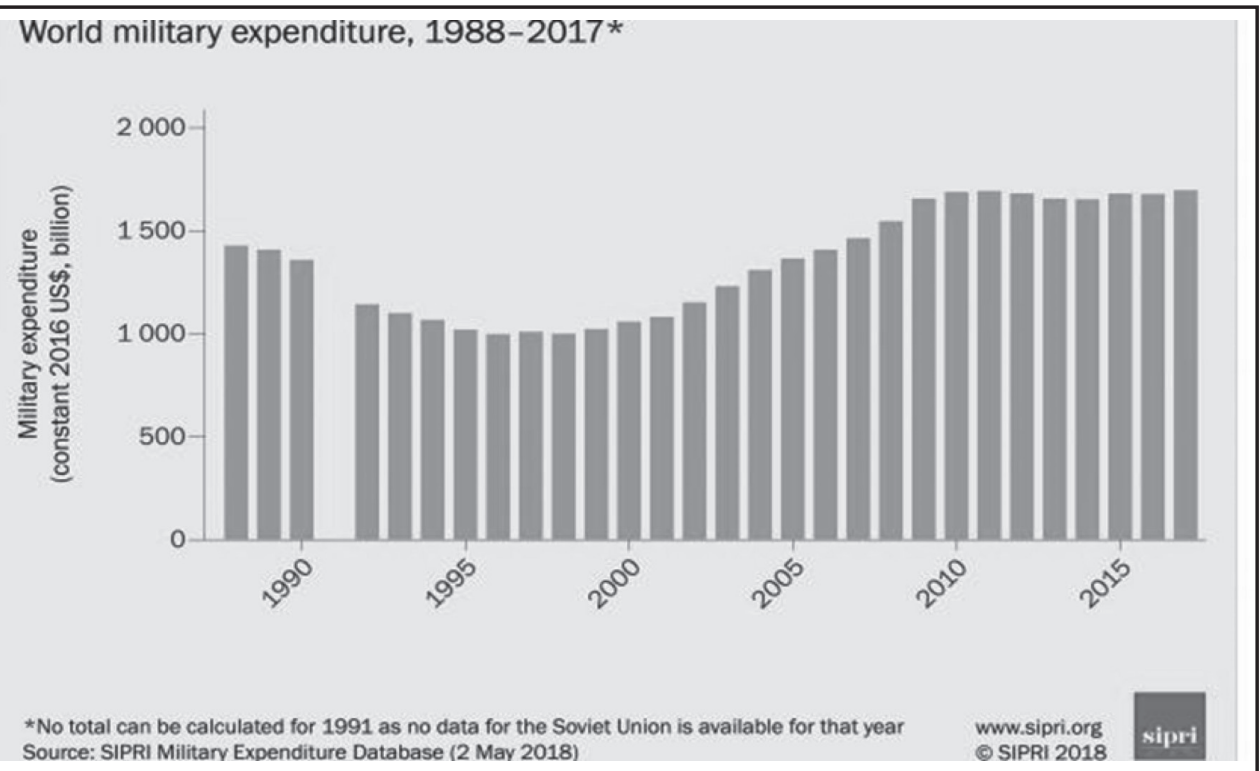

World military spending 1988-2017. Data and graphic: SIPRI 
- El gasto militar en 2017 representó el 2.2\% del PIB mundial, es decir, \$230 por persona.

- El gasto de China como porcentaje del gasto militar mundial ha aumentado del 5,8 por ciento en 2008 al 13 por ciento en 2017.

- Con \$ 66.3 mil millones, el gasto militar de Rusia en 2017 fue un 20\% más bajo que en 2016.

Los Estados Unidos siguen teniendo el gasto militar más alto del mundo. Con \$ 610 mil millones, el gasto militar de los Estados Unidos se mantuvo sin cambios entre 2016 y 2017. Sigue siendo la primera potencia militar: concentra el 35\% del gasto militar en el mundo. El gasto de Estados Unidos equivale al de los ocho países que siguen en el ranking.

Porcentajes de distribución del gasto militar en el mundo

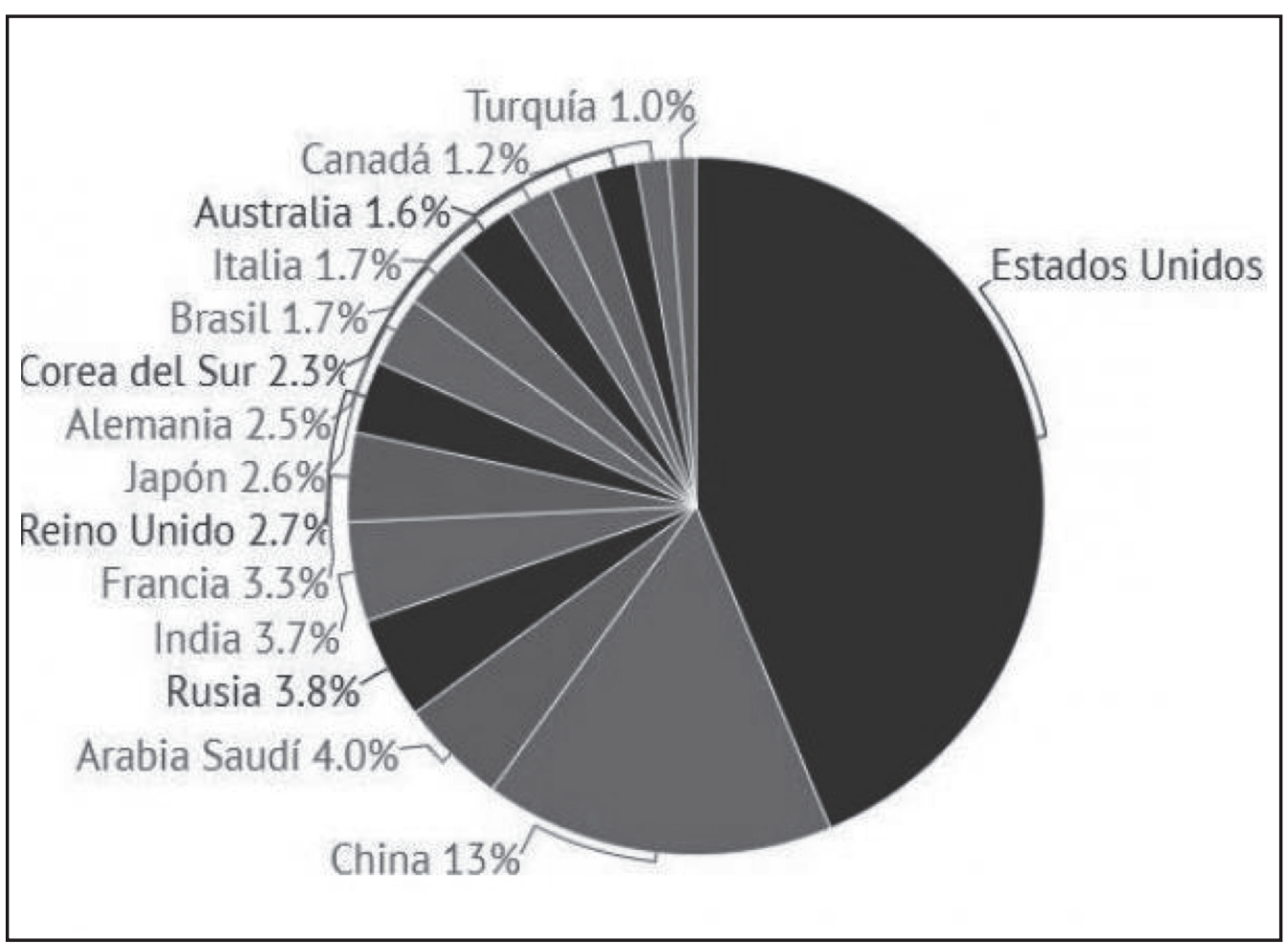

Fuente: (EL TIEMPO 2018)

La hegemonía norteamericana es asediada desde diversos lados; y el nuevo orden mundial se presenta descentrado en un multilateralismo inestable. Los límites de la hegemonía norteamericana "están en la desconexión entre el poderío militar y el menguado poder económico y deteriorada solvencia en el plano geopolítico" (Katz 2011). 
"Los Estados Unidos siguen siendo el poder capitalista dominante, pero conservan esta posición como resultado de los considerables esfuerzos que tienen que emprender para mantener su hegemonía en tres regiones clave" -Europa, Asia del Este y el Oriente medio- (Callinicos 2011).

Después de la Caída del Muro, el imperialismo norteamericano trató de consolidar su predominio mediante mecanismos bélicos hacia una nueva hegemonía. En la Primera Guerra de Irak, "la forma de control (...) es la que está abierta al capital, commodities e intercambio entre muchos Estados y empresas. No puede ser vista como una estrategia exclusiva económicamente, como parte de una forma depredadora de la hegemonía. Por el contrario, Estados Unidos utilizó su poder militar para diseñar un orden geopolítico que sirva de fundamento político para su modelo preferido de economía mundial: esto es, un orden internacional liberal cada vez más abierto. La política de Estados Unidos apuntó a la creación de una industria del petróleo internacional abierta, en la cual los mercados, dominados por las grandes empresas multinacionales, asignan capital y materias primas. El poder del Estado de Estados Unidos se despliega, no solo para proteger los intereses particulares de las necesidades de consumo y empresas de Estados Unidos, sino para crear las precondiciones generales de un mercado mundial petrolero, confiado en la expectativa que, como la economía líder, será capaz de satisfacer todas sus necesidades por medio del intercambio comercial” (Bromley 2005, 253-254, citado en Callinicos 2011, 115).

El soporte militar de la estrategia norteamericana es signo, no de su fortaleza, sino del debilitamiento de la hegemonía. "El viraje reciente hacia un imperialismo abierto respaldado por la fuerza militar norteamericana puede entenderse como un signo del debilitamiento de su hegemonía frente a las serias amenazas de recesión y devaluación generalizada en el país, que contrasta con los diversos ataques de devaluación infligidos previamente en otros lugares" (Harvey 2005, 100). La estrategia de dominio del imperialismo norteamericano acude a su fortaleza militar para contrarrestar la debilidad en los otros campos. "Estados Unidos goza hoy de una supremacía militar sin precedentes, pero la (segunda) Guerra de Irak pone de relieve los límites a las que, incluso, esta supremacía está sujeta" (Callinicos 2011, 122).

Con la llegada de Trump, los anuncios apuntan a un crecimiento permanente del gasto militar en la próxima década, con un incremento de las previsiones anteriores: (The White House Office of Management and Budget Mayo 2017).

\section{AÑO FISCAL}

2018

2019

2020

2021

2022

2023

2024

\section{PROPUESTA ANTERIOR}

549 mil millones USD

562 mil millones USD

576 mil millones USD

590 mil millones USD

605 mil millones USD

620 mil millones USD

636 mil millones USD
PROPUESTA ACTUAL

603 mil millones USD

616 mil millones USD

629 mil millones USD

642 mil millones USD

655 mil millones USD

669 mil millones USD

683 mil millones USD 
2025

2026

2027
652 mil millones USD

668 mil millones USD

685 mil millones USD
697 mil millones USD

712 mil millones USD

727 mil millones USD

Los anuncios se quedaron cortos. El 12 de diciembre de 2017, Trump firmó el presupuesto militar del 2018 cercano a los 700 mil millones de dólares: 626 mil millones para operaciones básicas, más 65.700 mil millones para misiones en el exterior, como Afganistán y Siria (EFE 2018).

Este incremento provocó una nueva carrera armamentista y la disputa en torno a tecnologías avanzadas. El Informe SIPRI (2018), señala que en el 2017 "se dio un aumento sustancial en el gasto militar de los países asiáticos y del Oriente Medio.” El teatro de los gastos se está desplazando del Atlántico al Pacífico.

3.3. La contradicción con los pueblos y países del Sur Clobal: "acumulación por desposesión".

"La idea (...) de que el capital se liberó de sus amarras geográficas sigue siendo un mito" (Callinicos 2011, 131). Esta tendencia se acentúa sobre todo después de la crisis del 2008, en que se establece una articulación entre el capital financiero y el capital rentista.

"El neoliberalismo no solo le dio a los capitalistas y administradores estatales la cohesión ideológica y la confianza en sí mismos para hacer retroceder al trabajo organizado, sino que legitimó la desregulación y la integración mundial de los mercados financieros; y una tendencia generalizada de apertura de mercados suministró capitales, ya sean industriales, comerciales o financieros, con el fin de buscar cada rincón y hendidura donde se pueda obtener una ganancia; a principios de la era neoliberal, Fredric Jameson señaló "una penetración y colonización, nueva e históricamente original, de la Naturaleza y el inconsciente" (1984: 78). Pero el neoliberalismo no tuvo éxito en llevar la rentabilidad a los niveles del gran boom" (Callinicos 2011, 136), y más bien se presentan diversas formas de contradicciones.

Entre las dos fuentes de bienes, la renta de la naturaleza y el trabajo, en nuestra América la predominancia ha estado en la fuente rentista. El dominio colonial y neocolonial ha operado en esta dirección. En el "nuevo imperialismo" la característica diferencial señalada por David Harvey sobre la "acumulación por desposesión" toma la forma sobre todo de desposesión de recursos estratégicos, de territorios comunales y de bienes públicos. Allí se traza una de las fronteras decisivas sobre las actuales confrontaciones geopolíticas, sobre todo en torno a Venezuela y la Amazonía.

Para solucionar las crisis de sobreacumulación de capital, "si no se producen devaluaciones sistémicas (e incluso la destrucción) de capital y fuerza de trabajo, deben encontrarse maneras de absorber estos excedentes. La expansión geográfica y la reorganización espacial son opciones posibles." Pero, a partir de las sucesivas crisis de sobreacumulación desatadas desde los 70, ya no son suficientes los mecanismos 
de "una serie de ajustes espacio-temporales que han fracasado", ni tampoco la volatilidad del capital con la retención de la crisis y el estallido de burbujas financieras en las periferias. Las crisis financieras, sobre todo a partir de la burbuja del punto com en el 2001, llegan al centro y, en particular, a la economía norteamericana. Y entonces, "la incapacidad de acumular a través de la reproducción ampliada sobre una base sustentable ha sido acompañada por crecientes intentos de acumular mediante la desposesión. Esta, según mi conclusión, es la marca de lo que algunos llaman "el nuevo imperialismo" (Harvey 2005).

La acumulación por desposesión tiene como teatro principal el Sur, y, en nuestro Continente, sobre todo la Amazonía. Un signo es el incremento del ritmo de deforestación en el nuevo milenio. La tendencia es a la reprimarización de las economías latinoamericanas y a la expansión del modelo extractivista, articulado al dominio del capital financiero.

La invasión del extractivismo adopta diferentes formas: minería en zonas de biodiversidad y en territorios de pueblos originarios, peaje global, agrocombustibles, monocultivos de exportación con transformaciones genéticas. Se combina la apropiación de la renta tradicional de la tierra y los recursos naturales estratégicos, con la apropiación de la renta tecnológica y los saberes de los pueblos.

Allí se opera un cambio sustancial. "El capital puede adquirir la capacidad de expansión mediante la doble incorporación de la fuerza de trabajo (incorporada como hemos visto con salarios deprimidos) y de la tierra (recursos naturales). Este capital ampliado se convierte cualitativamente en una nueva totalidad del sistema, un modo de acumulación que convierte fuentes no solo de plusvalía, sino fuentes de la plusvalia extra, o extraordinaria, convertidas en capital que se convierten en las determinaciones dentro el proceso laboral del capitalismo (no simplemente en la distribución de la plusvalía sino en su producción y realización). (...) El imperialismo modifica las relaciones esenciales de la producción capitalista y no solamente las formas de su distribución. La sobreexplotación de la fuerza de trabajo y el impulso a la plusvalía extraordinaria es una tendencia general y necesaria del capitalismo, entonces no tan extraordinaria. La plusvalía extra se puede obtener a través de tres mecanismos principales, que actúan por separado o en combinación: la sobreexplotación del trabajo mediante el empobrecimiento debido a bajos salarios y el agotamiento de la fuerza de trabajo; el agotamiento extractivo de los recursos naturales no renovables; y la captura del conocimiento tecnológico como monopolio privado. La unidad de estos mecanismos amplios y aparentemente muy diversos consiste en que son formas mejoradas de la explotación capitalista del trabajo que aprovechan y refuerzan la desigualdad nacional y la opresión social. La plusvalía extra no es entonces solo un concepto estrictamente económico, sino que se sustenta en la coerción como palanca extraeconómica reproducida en las relaciones sociales capitalistas" (Higginbottom 2018). 


\section{Las guerras: las nuevas fronteras}

Dos modificaciones son el punto de partida para el nuevo orden político mundial. La implosión de la URSS fue el argumento del "fin de la historia" y del "triunfo de Occidente" (Fujuyama 1988). Y el debilitamiento del funcionamiento del Estado-nación, y el surgimiento de una nueva forma de soberanía global, son la base para el nuevo orden político mundial que combina las formas imperialismo-imperio.

Para Negri-Hardt, la "hipótesis básica es que la soberanía ha tomado una nueva forma, compuesta por una serie de organismos nacionales y supranacionales unidos bajo una única lógica de mando. Esta nueva forma global de soberanía es lo que llamamos Imperio. La soberanía declinante de las naciones-Estado y su progresiva incapacidad para regular los intercambios económicos y culturales es, de hecho, uno de los síntomas principales de la llegada del Imperio" (Hardt y Negri 2000, 4). Aunque esta Mátrix no anula las contradicciones internas, ni la presencia de dinámicas nacionales.

El agotamiento del orden mundial westfaliano con el consiguiente debilitamiento de los Estados-nacionales, ha afectado al monopolio de la violencia física legitimada dentro de los territorios y las regiones. Y, en segundo lugar, después de la Caída del Muro, la ausencia de un Estado mundial y el debilitamiento de los organismos multilaterales, empezando por la ONU, son compensados por el predominio del poder del Estado norteamericano, como hegemón dentro de la comunidad internacional; lo que afecta al monopolio de la violencia física legitimada a nivel global, por lo cual se abre un período de disputas y violencias armadas en diversas regiones.

Según el SIPRI en la primera década del siglo XXI (2001-2010), se presentaron 69 conflictos armados, ${ }^{3}$ lo que representa una reducción cuantitativa respecto al período de la Guerra Fría. Y también habría una reducción del número de conflictos de alta intensidad, es decir en los que mueren más de mil personas (SIPRI 2012). El mayor número de víctimas son de la población civil: hoy el $90 \%$ de las víctimas mortales de los conflictos son civiles frente al $10 \%$ de militares. A lo que hay que sumar el alto número de desplazados: en 2012, según el Alto Comisionado de las Naciones Unidas para los Refugiados, la cifra era de 45,2 millones; la cifra más alta desde 1994, momento en que se alcanzó la de 47 millones (García 2013).

La mayoría de los conflictos se presentan como guerras civiles (80\%), pero están ligados a temas geoeconómicos (guerras por el petróleo, el agua, o el coltán) y a guerras geopolíticas, sobre todo en Asia Central y Medio Oriente.

En este tipo de registros no constan las nuevas violencias, ligadas a la "fascistización social" y la "mafiación de la política", que, a menudo cobran más víctimas que los conflictos bélicos. En nuestro Continente, el estado de guerra

3 Según el SIPRI, Los conflictos armados incluyen todos los conflictos entre dos partes que recurren al uso de la fuerza para resolver la incompatibilidad que les enfrenta, de las cuales al menos una es un gobierno de un Estado y que provocan al menos 25 muertes en un año. 
permanente durante más de sesenta años en Colombia, ha cobrado alrededor de 60 mil víctimas mortales, más 6 millones y medio de desplazados externos e internos. La frontera México-Estados Unidos es uno de los teatros más violentos en el mundo.

Las fronteras de las guerras se dan en el cruce de tres dinámicas: fronteras de recursos naturales estratégicos, sobre todo petróleo-agua-coltán; fronteras civilizatorio-religiosas-étnicas; fronteras geopolíticas.

Pierden fuerza los motivos territoriales e ideológicos, característicos del período de la Guerra Fría, y se principalizan los que giran en torno a las identidades religiosas, étnicas, razas, tribus, nacionalidades. "Entre 2001 y 2010 el 60\% de los conflictos no estatales se libraron entre comunidades étnicas o religiosas" (SIPRI 2012). Aunque estos motivos identitarios son más bien el detonante y subterfugio de disputas geopolíticas y geoeconómicas, sobre todo en el control de los recursos estratégicos, como sucede en las guerras de Medio Oriente o en las guerras olvidadas de África.

Y al mismo tiempo hay un proceso de privatización de las guerras y los ejércitos, en una escalada autoalimentada: "la privatización de la seguridad modifica también la dinámica de los conflictos armados. Y también tiene influencia sobre la gestión: la existencia y "normalización" de un mercado de la seguridad condiciona la resolución de los conflictos. En este mercado, las empresas militares y de seguridad privadas aseguran su negocio a través de la creación de nuevas necesidades. La tarea prioritaria de estas empresas no es convencer de la competencia técnica de los servicios que prestan sino crear la necesidad, es decir, convencer a los clientes (Estados, organizaciones internacionales, organizaciones no gubernamentales, empresas, etc.) de que necesitan sus servicios" (García 2013).

Con ello, entramos en una trasmutación del Estado moderno capitalista, el paso desde el Estado de derecho, al Estado de seguridad y a la segurización de la política, tanto a nivel local como global. "Las «razones de seguridad» han tomado el lugar de aquello que se llamaba, en otro tiempo, la «razón de Estado». Mantenimiento de un estado de miedo generalizado, despolitización de los ciudadanos, renuncia a toda certeza del derecho: éstas son tres características del Estado de seguridad. (...) el Estado de seguridad en el que estamos deslizándonos hace lo contrario de lo que promete, puesto que - si seguridad quiere decir ausencia de cuidado (sine cura) — mantiene, en cambio, el miedo y el terror. (...) es, por otro lado, un Estado policiaco, ya que el eclipse del poder judicial generaliza el margen discrecional de la policía, la cual, en un estado de emergencia devenido normal, actúa cada vez más como soberano. Mediante la despolitización progresiva del ciudadano, devenido en cierto sentido un terrorista en potencia, el Estado de seguridad sale al fin del dominio conocido de la política, para dirigirse hacia una zona incierta, donde lo público y lo privado se confunden, y cuyas fronteras provocan problemas para definirlas" (Agamben 2015). 
No se trata solo del viejo Leviatán de la modernidad temprana, sino de una estructura de control absoluto que invade los terrenos del deseo y lleva la violencia hasta los territorios íntimos de la vida.

A pesar de los discursos no estamos ante un sistema cerrado, la Mátrix encuentra puntos de fuga hacia adentro. Las guerras sobre los Estados-nacionales y sobre los territorios comunales, terminan en movilizaciones masivas de poblaciones, migraciones nacidas de las diversas formas de violencias, económicas, políticas, bélicas, ambientales, que invaden los territorios amurallados del centro y desequilibran los Estados de seguridad. ${ }^{4}$ El rostro del Otro absoluto abre, desde la negatividad, la pregunta sobre las alternativas.

\section{Los caminos de la paz}

En el extremo está la posibilidad de salida. Los signos son confusos y parciales. El antimperialismo, así sea contra el dominio americano, no es un ordenador suficiente para las luchas justas; hay que mirar las disputas geopolíticas, y también el ordenamiento y los procesos de democracia internos.

En Medio Oriente, las fronteras del conflicto se detienen, por un tiempo, en la Guerra de Siria, por la resistencia del Estado-nacional frente a una ofensiva de la alianza USA-Europa-Arabia Saudita-Israel, y el respaldo militar de Rusia que busca alejar el cerco bélico de sus fronteras materiales. El nuevo ataque de Trump contra los acuerdos con Irán, buscan empujar nuevamente las líneas hacia Oriente. En medio, los intentos de movimientos autónomos, como los del pueblo kurdo en Rojawa, corren el riesgo de terminar absorbidos en el juego geopolítico dominante.

Un ejemplo cruel sobre esta situación contradictoria es el conflicto de Sri-Lanka. La guerra civil desembocó en mayo del 2009 en el genocidio del pueblo Tamil. Sin embargo, por efecto de los alineamientos geopolíticos, no ha sido posible siquiera abrir una investigación independiente, bajo la dirección de la ONU, sobre las responsabilidades del gobierno y las Fuerzas Armadas.

En nuestra América, en Venezuela se presenta un desajuste entre los conflictos geopolíticos a partir del interés del imperialismo norteamericano sobre el control de recursos estratégicos, especialmente en el Orinoco, y el fracaso del proyecto bolivariano para una salida nacional y democrática.

Una hipótesis para una estrategia de paz podría partir de la transgresión de estos límites sistémicos en un paso más allá del Estado y la construcción de proyectos asentados en la comunidad. La lucha por la paz es, en primer lugar, una lucha ética, y, a partir de allí, política. Las formas extremas de explotación y de violencia del capitalismo tardío convierten a las luchas por la paz en un tema civilizatorio.

4 "Se calcula que en 2015 había 244 millones de migrantes internacionales en todo el mundo (3,3\% de la población mundial), lo que representa un incremento respecto de los 155 millones de migrantes estimados en el ańo 2000 (2,8\% de la población mundial)22. La migración interna es incluso más prevalente: las estimaciones mundiales más recientes indican que más de 740 millones de personas han migrado dentro de su propio país de nacimiento” (ONU Migración 2018, 15). 
En los períodos de estallidos de burbujas bélicas y neofascistas, regresa la pregunta formulada ante la emergencia del fascismo en los años 30 del siglo pasado, si se trataba de una excrecencia o de un resultado del capitalismo. Podemos retomar la respuesta de la Escuela de Frankfurt sobre la naturaleza de la modernidad capitalista asentada en el imperialismo de la razón instrumental, para ampliarla al dominio de la razón cínica y de una violencia vital, el paso al thanatos-bio-poder, como forma de dominio. La alternativa por la paz se basa en la crítica a la modernidad capitalista. Podemos retomar las tesis éticas de Lévinas, nacidas de la experiencia extrema de los campos de concentración, sobre el Desear como pulsión creadora, hasta descubrir en el Otro extremo, en la víctima, la posibilidad de la responsabilidad humana, la trascendencia que junta el goce con la gratuidad:

"El ser que se expresa se impone, precisamente llamándome desde su miseria y desnudez sin que pueda cerrar mis oídos a su llamado (...) Dejar a seres humanos sin comida es una falta que ninguna circunstancia atenúa; aqui no se aplica la distinción de lo voluntario e involuntario (...) Ante el hambre de los seres humanos la responsabilidad se mide objetivamente (...) Al develamiento del ser en general (Heidegger), como base del conocimiento y como sentido del ser, pre-existe la relación con el ente que se expresa (el Otro); a nivel ontológico (le antecede) el nivel ético" (Lévinas, Totalidad e infinito 1977, 175. Citado en Dussel 1988, 363).

"La razón ética -que es la única razón sostenible- nace de la responsabilidad por el otro" (Dussel 1998, 367). Allí asienta Lévinas la racionalidad de la paz:

"Res-ponsabilidad por el otro o comunicación, aventura que contiene todo discurso de la ciencia y la filosofía. Por ello, esta res-ponsabilidad sería la racionalidad misma de la razón o su universalidad, la racionalidad de la paz" (Lévinas 1987, 203. Citado en Dussel 1988, 367).

La estrategia belicista y el armamentismo implica un problema ontológico de anulación de la vida. La alternativa empieza por el reconocimiento de la precariedad de la vida, "implica vivir socialmente, es decir, el hecho de que nuestra vida está siempre, en cierto sentido, en manos de otro", a muchos de los cuales ni siquiera conocemos podemos nombrar. "Pero la implicación social de este planteamiento es, precisamente, que el «nosotros» no se reconoce ni puede reconocerse; que está escindido desde el principio, interrumpido por la alteridad, como ha dicho Levinas, y que las obligaciones que «nosotros» tenemos son, precisamente, las que desbaratan cualquier noción establecida del «nosotros»" (Butler 2010, 30-31).

En las periferias, las estrategias de exclusión del otro adoptan sus propias formas. A los dispositivos económicos de la modernidad capitalista basados en la sobreexplotación del trabajo y la naturaleza y en la acumulación por desposesión de bienes comunes, bienes comunitarios y bienes públicos, se superponen mecanismos de dominio civilizatorio, en torno a dos dinámicas principales. De un lado, el racismo, como fundamento del eurocentrismo y la colonialidad del poder, en términos de 
Aníbal Quijano (2000), o la blanquitud en los de Bolívar Echeverría: "El racismo normal de modernidad capitalista es un racismo de la blanquitud. Lo es, porque el tipo de ser humano que requiere la organización capitalista de la economía se caracteriza por la disposición a someterse a un hecho determinante: que la lógica de la acumulación del capital domine sobre la lógica de la vida humana concreta y le imponga día a día la necesidad de autosacrificarse, disposición que sólo puede estar garantizada por la ética encarnada en la blanquitud. Mientras prevalezcan esta organización y este tipo de ser humano, el racismo será condición indispensable de la "vida civilizada"." (Echeverría, Imágenes de la "blanquitud" 2011, 160).

El racismo se funda en la conquista colonial, en particular de América Latina. La primera pregunta que se hace el conquistador cuando llega a la Abya Yala, es si los indios tienen alma; con ello, más allá de la respuesta y de la presencia de posiciones humanistas como la de Las Casas, se quiebra la posibilidad de reconocimiento del otro, de la constitución del nosotros; y se abre una dinámica de violencia estructural, que puede variar en el tiempo, pero se presenta como el fundamento de las diversas formas de dominio y explotación.

$\mathrm{Y}$, de otro, un patriarcalismo violento que arrasa con las bases comunitarias de los pueblos y genera espacios de violencia absoluta, sobre todo en contra de las mujeres, las niñas-niños y adolescentes, como el punto extremo del desconocimiento del carácter de la humanidad del otro (Saltos 2018).

Este camino se hace con marcas coyunturales, respuestas a las circunstancias concretas. El primer paso es una visión autocrítica sobre las causas de la derrota. En la coyuntura actual, en nuestra América, respecto a la "racionalidad de la paz", la pregunta más inquietante es respecto a la cuestión de la democracia. "La democracia y los derechos humanos han sido militarizados" (Bo-hiuk 2014) (CWM 2018) por parte del imperialismo. Empero, al frente queda la incapacidad de los "gobiernos progresistas" para profundizar la democracia, incluso bajo su forma representativa-liberal como solución pacífica de conflictos bajo reglas, y la instauración de formas autoritarias de control y prácticas de corrupción institucionalizada, que han ilegitimado a los diferentes regímenes, abriendo paso al retorno de gobiernos de ultraderecha. No es una derrota coyuntural, sino que alude a la raíz de la derrota de los intentos alternativos al capitalismo, el entrampamiento en torno al Estado como solución y el renunciamiento al poder desde abajo.

\section{Las estrategias de paz en la frontera}

6.1. El 13 de abril de 2018, el presidente del Ecuador, Lenin Moreno, confirmó la muerte de tres trabajadores del diario El Comercio, el periodista Jorge Ortega, el fotógrafo Paúl Rivas y el conductor Efraín Segarra, secuestrados el 26 de marzo por un grupo disidente de las FARC, encabezado por alias Guacho. Estos asesinatos se sumaron al de cuatro militares, caídos en un ataque de los disidentes, en Mataje, un poblado en la frontera con Colombia. La oleada de violencia co- 
menzó el 27 de enero, con la explosión de un carro bomba en el Comando Policial del cantón San Lorenzo.

A raíz de estos acontecimientos se abrió un debate sobre las estrategias de respuesta. Una estrategia de guerra, en la línea del Plan Colombia, impulsado en el vecino país a partir de 1991, en contra del terrorismo, la guerrilla y el narcotráfico, con resultados contraproducentes y la prolongación de un estado de guerra permanente. La tendencia oficial, aunque se habla de una respuesta integral que implica la atención a una zona olvidada por los dos Estados, apunta a la respuesta de guerra asimétrica.

Al frente se levantaron voces que buscaban una salida diferente. Monseñor Eugenio Arellano, presidente de la Comisión Episcopal Ecuatoriana y obispo de Esmeraldas, proclamó: "El de la paz es un camino difícil, pero necesario para el progreso de los pueblos." Alertó: "la frontera del Ecuador donde suceden estas cosas no es una frontera viva", sino que es "una frontera muy pobre". "Hay pocos caseríos, la educación no está bien, la salud tampoco y los jóvenes no encuentran oportunidades". De ahí que "la tentación de la guerrilla o la tentación de la droga sean muy grandes". Agregó otra preocupación: "ahora que han muerto estas personas, la tentación de nuestro gobierno es el de una fuerte intervención militar". Señaló categóricamente que la paz no nace del fuego", "la paz es una fruta que nace del árbol de la justicia". Una afirmación que, según el prelado, parte del ejemplo del vecino país: "Colombia lleva cuarenta ańos invirtiendo en armas y no ha conseguido sofocar la violencia". "Es momento de dar oportunidades a los jóvenes con trabajo digno, es el momento de tenderles una mano promoviendo el desarrollo de la zona, (...) el desarrollo es el nuevo nombre de la paz”. Desde esta visión, Monseñor Arellano intentó mediar para un canje de prisioneros, pero las vacilaciones e interferencias de los operativos militares desde los dos lados de la frontera, precipitaron las muertes (Arellano 2018).

6.2. El 16 de abril de 2016 un terremoto de magnitud 7,8 Mw afectó a las provincias de Manabí y Esmeraldas. Muisne, ubicada en el sur de la provincia de Esmeraldas, cercana al epicentro, fue uno de los poblados más afectados con el colapso de 803 viviendas y la suspensión de servicios básicos por varios días; aunque no existieron víctimas mortales. La población, ante la ausencia inicial del Estado, asumió la atención a las víctimas y la supervivencia en condiciones precarias.

La intervención del Estado se orientó al desplazamiento de la población del sitio ancestral, ubicado en la Isla, para trasladarlos a un nuevo terreno "seguro" a 2,5 km. La ingeniera Susana María Dueñas de la Torre, Secretaria de Gestión de Riesgos, en la Resolución No SGR-073-2016, del 21 de junio de 2016, declara "en zona de riesgo a toda la Isla que es afectada por inundación de Tsunami según carta de Inundación 080350-Muisne, Provincia de Esmeraldas" (Art. 2). Y, "en virtud de esta declaratoria se prohíbe los asentamientos humanos en la zona declarada de riesgo, de conformidad con lo establecido en la Disposición General Décimo Cuarta del Código Orgánico de Organización Territorial, Autonomía y Descentralización” 
(Art. 3). Surgen diversos signos de la aplicación de estrategias de vaciamiento poblacional del territorio ante intereses de empresas turísticas para ubicarse en la Isla.

Sectores crecientes de la población defendieron el derecho a permanecer en su territorio ancestral, tanto más que la Resolución se tomó sin la consulta previa correspondiente y sin una base técnica comprobada. Progresivamente la totalidad de la población se reasienta en la Isla.

En este período, los problemas de la Isla de Muisne, no se refieren al riesgo de tsunami, sino a la desatención del Estado y a la crisis institucional local. Se trata de uno de los cantones más afectados por la pobreza bajo sus diferentes formas: desempleo, insalubridad, falta de vivienda, analfabetismo, etc. Pero, además, es una zona atravesada por la presencia de las mafias nacionales y transnacionales del narcotráfico, del tráfico de armas y de personas.

La defensa del derecho al territorio por parte de la población, con apoyo de la Iglesia y de los movimientos sociales, frente a la violencia del Estado y del crimen organizado, se articula a una estrategia de paz, sometida a riesgo permanente. Líder Góngora, el principal dirigente popular de la zona, y ahora candidato a Alcalde del Cantón, propone un plan de paz que permita la convivencia de todos y el desarrollo integral del Cantón. Cuando le preguntamos qué va a hacer con las mafias, señala: "Nuestro pueblo ha aprendido a vivir en el riesgo. Podemos buscar un camino de negociación que respete el Cantón como zona de paz, libre de la producción y procesamiento de la droga, que no induzca a los jóvenes al consumo, y que se abra a una progresiva regularización de la vida. No les tenemos miedo, pero hay que hablar. Y hay que lograr que el Estado, en lugar de una política de violencia, contribuya a una política que elimine las condiciones por las cuales la juventud y los pobladores se ven tentados por los beneficios de los narcotraficantes. Tenemos grandes potencialidades, sobre todo en torno a la agricultura y el turismo, para salir de la dependencia de la economía del narcotráfico." Le insistimos, "su vida puede estar en riesgo." Responde con sencillez conmovedora, "No soy un héroe ni un mártir. Yo no quería asumir esta responsabilidad, pero la gente me la asignó. Es una responsabilidad ante nosotros, no asumirla sería condenarnos a la muerte. A pesar del riesgo, hay que darle una oportunidad a la vida. Sé que no estoy solo, soy parte de la comunidad, la salida viene de la fuerza del pueblo y de la organización".

6.3. Quizás es solo el grito desesperado por defender la vida, el mismo que señala Lévinas en la experiencia del campo de concentración. ${ }^{5}$

"La biopolitica se legitima desligándose de todo lazo social, de toda ley común, condenando a la mayoría de las personas a una economía restringida a mera conservatio vitae" (Bustelo 2007, 94). El camino de retorno, ligar la vida del individuo como sujeto de las comunidades, ligar los derechos humanos a los temas de la riqueza y el poder, ligar los derechos negativos a los derechos por una vida digna, puede señalar la puerta de salida.

5 Retomo algunos argumentos tratados en mi artículo "Puer sacer: la violencia absoluta", abril 2018. 
En la visión de Lévinas: "El "otro" en su dimensión de alteridad absoluta exige una ética de responsabilidad infinita. (...) La experiencia humana se da por la posibilidad del ser humano de "ser para otro" en una relación ética que implica el cuestionamiento absoluto del yo" (Bustelo 2007, 102).

Ante la violencia absoluta, la ética absoluta: "La critica no reduce lo Otro al Mismo como la ontología, sino que cuestiona el ejercicio del Mismo. Un cuestionamiento del Mismo -que no puede hacerse en la espontaneidad egoista del Mismo- se efectúa por el Otro. A este cuestionamiento de mi espontaneidad por la presencia del Otro, se llama ética" (Levinas 1997).

Allí surge el aporte de la otra visión, desde los pueblos originarios de nuestra América, el sentido de la comunidad como ser-con-nos-otros. No una renuncia al yo, sino la creación de un nuevo campo compartido, un nos-otros.

Partir de que las identidades son construidas y, por tanto, pueden encontrar cauces de re-conocimiento. "La disposición a la autotransformación, la aceptación dialógica -no simplemente tolerante- de identidades ajenas, viene precisamente de la asunción de lo contingente que hay en toda identidad, de su fundamentación en la pura voluntad política, y no en algún encargo mítico ancestral, que por más terrenal que se presente termina por volverse sobrenatural y metafísico. Esta disposición es la que da a la afirmación identitaria de las mayorías latinoamericanas -concentrada en algo muy sutil, casi solo una fidelidad arbitraria a una "preferencia de formas"-, el dinamismo y la capacidad de metamorfosis que serían requeridos por una modernidad imaginada más allá de su anquilosamiento capitalista" (Echeverría, América latina: 200 años de falatalidad 2011, 229).

México, diciembre 2018

\section{Referencias}

Agamben, Giorgio. Del Estado de derecho al Estado de seguridad. Editado por Le Monde. 23 de diciembre de 2015. http://artilleriainmanente.blogspot. com/2015/12/giorgio-agamben-del-estado-de-derecho.html?spref=fb (último acceso: 4 de Diciembre de 2018).

Arellano, Eugenio. «La paz es un fruto que nace del árbol de la justicia». Abril de 2018. https://www.revistaecclesia.com/monsenor-arellano-ecuador-la-paz-es-unfruto-que-nace-del-arbol-de-la-justicia/ (último acceso: 8 de Diciembre de 2018).

Arrighi, Giovanni. El largo siglo XX. Dinero y poder en los orígenes de nuestra época. Segunda. Traducido por Carlos Prieto. Madrid: Siglo XXI, 2014.

Bo-hiuk, Suh. «La militarización de los derechos humanos coreanos: una perspectiva peninsular». Asian studies 46, no 1 (2014): 3-14.

Bromley, Simon. «The United states and control of world oil». Government and Opposition, no 40 (2005). 
Bustelo, Eduardo. El recreo de la infancia. Argumentos para otro comienzo. Primera. Buenos Aires: Siglo XXI Editores Argentina, 2007.

Butler, Judith. Marcos de guerra. Las vidas lloradas. México: Paidós, 2010.

Callinicos, Alex. «El imperialismo y la economía política hoy». Editado por

CLACSO. Crítica y emancipación, Año III, N 5 (Primer semestre 2011): 111 166.

Coghlan, Andy, y Debora MacKenzie. «Revealed - the capitalist network that runs the world». Editado por NewScientist. 19 de Octubre de 2011. https://www. newscientist.com/article/mg21228354-500-revealed-the-capitalist-networkthat-runs-the-world/ (último acceso: 31 de Octubre de 2018).

CWM. «Reclamando el carácter sagrado de vidas, tierras y mares. Un proceso de estudio para la mejora de la resistencia y la solidaridad». Documento conceptual, 2018.

Dierckxsens, Win, y Walter Fomento. «Un agónico final de la globalización: ¿Cambio civilizatorio?» En Diálogos con el pensamiento de Francois Houtart, de Varios. Quito, 2018.

Dumont, Louis. Ensayos sobre el individualismo. Una perspectiva antropológica sobre la ideología moderna. España: Alianza Universidad, 1987.

Dussel, Enrique. Ética de la liberación en la edad de la globalización y la exclusión. Madrid: Trotta, 1998.

Echeverría, Bolívar. "América latina: 200 años de falatalidad». En Crítica de la modernidad (Antología), de Bolívar Echeverría, 221-229. La Paz: Vicepresidencia del Estado Plurinacional de Bolivia, 2011.

Echeverría, Bolívar. "Imágenes de la "blanquitud”". En Crítica de la modernidad capitalista (Antología), de Bolívar Echeverría, 145-160. La Paz: Vicepresidencia del Estado Plurinacional de Bolivia, 2011.

EFE. «Presupuesto militar de Trump: 700.000 millones de dólares». 12 de diciembre de 2018. https://www.elpais.com.uy/mundo/presupuesto-militar-trump-millones-dolares.html (último acceso: 31 de Octubre de 2018).

EL TIEMPO. "¿Qué países tienen el mayor gasto militar?» 26 de septiembre de 2018. https:/www.eltiempo.com/mundo/gasto-militar-en-el-mundo-aumenta-en-2018-273678 (último acceso: 31 de Octubre de 2018).

Elliot, Larry. "No le crean al Banco Mundial: los robots se quedarán con nuestros salarios». The Guardián, Octubre 2018.

Fukuyama, Francis. «El fin de la historia». The National Interest, 1988.

García, Caterina. "Las "nuevas guerras” del siglo XXI. Tendencias de la conflictividad armada contemporánea». Editado por Institut de Ciències Polítiques i Socials. Universitat Autónoma de Barcelona. Working Papers, no 323 (2013). Hardt, Michael, y Toni Negri. Imperio. Cambridge, Massachussets: Harvard University Press, 2000.

Harvey, David. «El “nuevo” imperialismo: acumulación por desposesión». Editado 
por CLACSO. Socialist register 2004, 2005: 99-129.

Hernández, Fernando. «Escala la tensión en el mar de China Meridional». Editado por Facultad de Estudios Globales de la Universidad Anáhuac México. 20 de agosto de 2018. http://revistafal.com/escala-la-tension-en-el-mar-de-china-meridional/ https:/ecuadortoday.media/2018/07/20/escala-la-tension-en-el-marde-china-meridional/ (último acceso: 8 de noviembre de 2018).

Higginbottom, Andy. Estructura y esencia en El Capital I: la plusvalía y el capitalismo globalizado. London: Kingston University, 2018.

Hung, Ho-fung. «Rise of China and the global overaccumulation crisis». Review of International Political Economy, no 15 (2008).

Jaramillo, Pablo. Etnografías en transición: escalas, procesos y composiciones. 16 de febrero de 2013. https://revistas.uniandes.edu.co/doi/pdf/10.7440/antipoda16.2013.02 (último acceso: 29 de Noviembre de 2018).

Katz, Claudio. Bajo el imperio del capital. Buenos Aires: Ediciones Luxemburg, 2011.

Lévinas, Emmanuel. De otro modo que ser o más allá de la esencia. Salamanca: Sígueme, 1987.

Levinas, Emmanuel. Totalidad e infinito. Salamanca: Sígueme, 1997.

Lévinas, Emmanuel. Totalidad e infinito. Salamanca: Sígueme, 1977.

Melville, Herman. Billy Bud, marinero. 1891.

ONU Migración. Informe sobre las migraciones en el mundo 2018. Informe OIM, Suiza: OIM, 2018.

OXFAM internacional. Informe anual 2018. Premiar el trabajo, no la riqueza. OXFAM GB, 2018.

Quijano, Aníbal. «Colonialidad del poder, eurocentrismo y América Latina». En La colonialidad del saber: eurocentrismo y ciencias sociales. Perspectivas latinoamericanas, de Edgardo Lander (compilador), 201-246. Buenos Aires, 2000.

Ramas, Clara, y Jorge Tamames. "Trump es un paso hacia nuestro objetivo, pero es insuficiente". Entrevista a Aleksandr Dugin. 28 de noviembre de 2018. https:// ecuadortoday.media/2018/11/28/trump-es-un-paso-hacia-nuestro-objetivo-pero-es-insuficiente/ (último acceso: 28 de Noviembre de 2018).

Saltos, Napoleón. «Puer sacer: la violencia absoluta. PDF». 2018.

SIPRI. «Global military spending remains high at \$1.7 trillion». Estocolmo, 2018.

SIPRI. Year Book 2012. Armaments, Disarmament and International Security. Estocolmo: SIPRI, 2012.

The White House Office of Management and Budget. «Una Nueva Fundación para la Grandeza Americana». Washington DC, Mayo 2017. Veraza, Jorge. Subsunción real del consumo al capital. México: Itaca, 2008. 